\title{
JAIME TORRES BODET Y LAS PEDAGOGÍAS MASCULINAS: EDUCACIÓN, HOMOSOCIABILIDAD Y BIOTEXTUALIDAD EN MÉXICO (PRIMERA MITAD DEL S. XX)
}

Jaime Torres Bodet and the Male Pedagogies: Education, Homosociability and Biotextuality in Mexico (first half of the 20th Century)

\author{
MAUricio Zabalgoitia HERrera \\ Universidad Nacional AutónOma de MÉxico (MÉxico) \\ mauricio.zabalgoitia@gmail.com https://orcid.org/0000-0003-0806-0887
}

\section{RECIBIDO: 6 DE MARZO DE 2018}

ACEPTADO: 28 DE AGOSTO DE 2018

RESUMEN: Bajo una noción amplia de educación como marco, lo que es a la vez cultural, literaria y de la vida social y cotidiana, en este trabajo se cartografía la figura de Jaime Torres Bodet desde una marcada perspectiva sexo/género, y como vida ejemplar, al grado de proponerse una radiografía de lo biográfico como un cuerpo textual; a esto se lo denomina biotextualidad. Desde esta noción, sumada a versiones recientes de historiografía, la noción de autor e intercalando el discurso de Judith Butler sobre la normativa del género, se dialoga con la cultura letrada y la educación en México hasta llegar a sugerirse en este entramado al género como un extremo oculto de la historiografía. A partir de ahí se abordan los poderes de nuevos caballeros de las letras, y con la vida de Torres Bodet como vehículo (de su infancia a la primera y segunda juventud) se observa el reforzamiento de espacios y redes homosociales masculinas tanto nacionales como internacionales; de sus poses, ideales, lugares y prácticas sexoculturales; de los usos y alcances de lo masculino y las definiciones del Hombre y los hombres. Finalmente, la biotextualidad del educador, poeta e intelectual mexicano es leída como una versión de las "pedagogías masculinas"; a decir, dispositivos de educación, representación y aleccionamiento cuya función es construir y negociar las definiciones de los personajes de la vida moderna.

PALABRAS CLAVE: Jaime Torres Bodet, educación, género, biotextualidad, homosociabilidad, pedagogías masculinas.

ABSTRACT: In this work the figure of Jaime Torres Bodet is cartographed from a strong sex/gender perspective, and as an exemplary life, taking as an starting point a broad notion of education as a framework, what it means: culturally, literary and from social and daily life. Thereby a radiography of a biographical possibility as a textual body is carried out. This is what we called biotextuality. From this notion a dialogue is undertaken with literate culture and education in Mexico, added to recent versions of historiography, the idea of autor and a interspersing with the work of Judith Butler on the regulation of gender. In this process gender is proposed as the "hidden end" of historiography, and the powers of new caballeros de las letras are approached. And with the life of Torres Bodet as a vehicle (from his childhood to the first and second youth) we observe the reinforcement of homosocial spaces and networks, both national and international; of their poses, ideals, places and sex-cultural practices; of the uses and scope of the masculine world and the definitions of Man and the men. Finally, the biotextuality of the Mexican educator, poet and intellectual is read as a version of the "masculine pedagogies". This means: devices of education and representation whose its function is to build and negotiate the definitions of the characters of modern life.

KEYWORDs: Jaime Torres Bodet, Education, Gender, Biotextuality, Homosociability, Male Pedagogies. 
Un texto no es un texto más que si se esconde a la primera mirada, al primer llegado la ley de su composición y la regla de su juego.

-Jacques Derrida, "La farmacia de Platón" (1968).

No existe una identidad de género detrás de las expresiones de género; esa identidad se construye performativamente por las mismas "expresiones" que, al parecer, son resultado de ésta. -Judith Butler, El género en disputa (1990).

\section{INTRODUCCIÓN. BIOGRAFÍA, EDUCACIÓN Y SISTEMA SEXO/GÉNERO1}

Los estudios de género que han resultado de la revolución del feminismo se han venido interesando por lo biográfico y las historias de vida -en sentido amplio-, y desde puntos de vista tan dinámicos como radicales. En pocas palabras, se trata de un espectro que va de las vertientes autobiográficas a las aproximaciones a espacios en los que la historia cuenta otros relatos si es que la vida de determinadas figuras se toma como material historiográfico. ${ }^{2}$

Otro tema, sin duda, y no exento de las polémicas que surgen de los postulados en sí del quehacer feminista, lo constituyen aproximaciones biográficas críticas o deconstructivas sobre figuras masculinas. Estos acercamientos, sean desde una mirada oblicua o transversal, son llevados a cabo desde sus propios discursos autobiográficos, desde reconstrucciones de sus historias de vida, o incluso a partir de testimonios. En todos los casos, estos varones son tomados como figuras destacadas de lo cultural, lo social o lo político, y en lo que aquí nos interesa, funcionan siempre como ejemplos de prácticas sexoculturales determinantes o promotoras de cambios en el orden de lo sexual o lo genérico. A este respecto, cabe decir que mención aparte merecen trabajos que provienen de los estudios queer. Ahí, desde una dinámica mirada, la vida de mujeres, hombres, gays, lesbianas y una diversidad de expresiones sexogenéricas han abierto un campo novedoso en el que la historia de la vida privada se erige como instancia para desmontar las versiones heteropatriarcales y falogocentristas de ciertos ideales de mundo.

Volviendo, entonces, a las figuras de masculinidad destacadas, en este trabajo argumentamos que sus vidas en sí pueden servir como material novedoso en procesos de producción históricos un tanto alternativos. Y que desde un marcado interés por el género, incluso pueden sugerirse como instrumentos de una historiografía educativa particular.

\footnotetext{
1 Este trabajo se adscribe a la labor de investigación desempeñada en el IISUE de la UNAM, al grupo de investigación Pedagogías de género. Educación, literatura y cultura en México (s, XIX y XX) y al proyecto: "Pedagogías masculinas. Educación superior, género y nación a la luz de los campos universitario e intelectual en México (S. XIXXX)" (PAPIIT: IA400618; DGAPA-UNAM).

${ }^{2}$ A este respecto, podemos mencionar a autoras como Heilbrun (1984), Miller (1991), Siegel (1999) o Leggot (2001), “entre otras” en el ámbito anglosajón; o García de León (2009) en el hispánico, y de manera destacada, a Reyes (2005) en el mexicano. En esta línea, cabe mencionar una nutrida vertiente acerca de la historia de las mujeres en México en espacios culturales, universitarios y profesionales, desde perspectivas en las que el ejemplo vital -una suerte de vida ejemplar de género - es material para nuevas historiografías. Por destacar sólo algunos trabajos, se pueden mencionar a Lau (2006) y su trabajo acerca del Ateneo de mujeres; o desde el ámbito universitario a Alvarado (2004); o a Buquet, Coope, Mingo y Moreno (2013).
} 
Para explorar y desarrollar esta propuesta, tomamos el caso de vida (ejemplar) del escritor, poeta, diplomático y educador mexicano Jaime Torres Bodet (1902-1974). Este, como es bien conocido desde historiografías tradicionales e intelectuales, se erige como un pilar de los fundamentos educativos, y de formación cultural e intelectual en el México moderno. En la línea de Justo Sierra y José Vasconcelos, Torres Bodet atraviesa, como sujeto masculino de su tiempo, al siglo y a la cultura mexicana definiéndola no sólo en términos de proyectos educativos y culturales formales, sino, y es lo que queremos primar, en cuanto a un proyecto igualmente productor de bienes culturales y pedagógicos. ${ }^{3}$ Este sería el de un sistema sexo/género mexicano, el cual operaría a partir de una definición laxa de lo educativo. Se trata, a manera de introducción, de prácticas y discursos de enseñanza que emanan de una noción de educación que es a la vez social, cultural y de la vida cotidiana, porque, como bien lo expresa Gayle Rubin en el capital texto en el que lo nombra, por falta de un término más "elegante”, “[...] un `sistema de sexo/ género' es el conjunto de disposiciones por el que una sociedad transforma la sexualidad biológica en productos de la actividad humana, y en el cual se satisfacen esas necesidades humanas transformadas" (Rubin, 1986: 97).

En cuanto a esa noción de educación que esbozamos, por una parte podemos ligarla a lo que desde el feminismo postestructural se acomete en términos de entenderla como uno más de los fenómenos de enorme amplitud que debería desmontarse en cuanto a sus significados y su implicación en la correspondencia foucaltiana entre saber y poder (Luke y Gore, 1992: ix). Asimismo, queremos invocar una idea de lo educativo que haga énfasis en la "[...] centrality of subjectivity, identity and knowledge"; $y$, acaso, en un esfuerzo general por romper "[...] with the kinds of discourse and theory-building that have reamained under the control of men" (ix). Por otra, buscamos separarla de las definiciones y fenómenos de la educación formal y concebirla, por lo menos en este contexto específico, como una pedagogía cultural de género. Como una instancia semiótica, performativa, e incluso performática subyacente a los sistemas más cargados de significados en la conformación de las naciones modernas y sus simbologías: los de la cultura en sí, los de lo social, lo político, y los de lo educativo formal, ahora sí, en un proceso de retorno. Es por eso que en este marco la idea de lo educativo se cifra ahí en donde dispositivos culturales,

\footnotetext{
${ }^{3}$ En cuanto a las relaciones entre educación -o pedagogía - y género es importante mencionar que frente a una fértil diversidad de enfoques y estudios que van de los feminismos a las masculinidades, y de ahí a la teoría queer, hay algunos puntos de vista y labores que bien podemos remarcar; unos de carácter general, y otros centrados en la experiencia mexicana y desde una perspectiva abiertamente historiográfica. En términos globales, y desde el feminismo, es posible nombrar una diversidad de trabajos de Carmen Luke o Jennifer Gore (aquí referimos uno de 1992), los cuales se han concentrado en cuestiones un tanto recientes de educación formal: currículo, instituciones, aulas, pedagogía crítica o radical, etc. En términos queer ha habido una aproximación fértil a las llamadas pedagogías culturales desde, por lo menos, el volumen de John Landreau y Nelson Rodriguez (2010). Ahora bien, en cuanto a la cuestión mexicana, y desde la historia del género y las mujeres, mencionamos unos pocos casos incidentes, como los trabajos de Eli Bartra (1997) a finales de los 90 o los de Ma. De Lourdes Alvarado (2004) centrados en el siglo XIX. En cuanto al género como categoría más amplia y su incidencia en lo educativo, los de Cristina Palomar (2003) y Frida Gorbach (2008). Para otorgar un brevísimo esbozo de las posibilidades que otorga la triada educación, masculinidades e historiografía en México, los de Ana Amuchástegui e Ivone Szasz (2007), los de Robert Buffington (2016), dirigidos a los modelos de hombría en pugna desde el Porfiriato y hacia la Revolución, o los varios de Robert M. Irvin $(1998,2015)$, mucho más centrados en la homosexualidad, el homoerotismo o la historia de la cultura gay. Finalmente, desde una perspectiva cercana a los estudios culturales, hay que destacar la labor de Gabriela Cano (2009, 2011), entre otros/as tantos/as investigadores/as.
} 
discursivos y vitales -que a su vez son tecnologías de género 4 - acometen funciones instructoras, aleccionantes y modelizantes de conciencias, esto último en referencia al trabajo de Manuel Asensi (2011; 2017). Estas tecnologías de género (masculino) cumplen con la función no solo de educar o formar ciudadanos, sino de cuidar y mantener los espacios de homosociabilidad masculina; ya que desde ahí el varón se proyecta a la esfera pública, y hacia todo lo ajeno al hogar, vinculándose a la nación, a la cultura letrada y a lo que Víctor Macías-González llama la “república patriarcal” (2007: 57).

Ahora bien, para comenzar debemos apuntar ciertos puntos de partida para un recorrido que se plantea como de género a priori, en tanto que se acomete a partir de las etapas que constituyen la vida occidental contemporánea, y que determinan a un "hombre", a decir: niñez, juventud y adultez; constructos culturales que desde el psicoanálisis y el feminismo se han venido desmontando. Este trayecto es el que nos permite proponer un acercamiento a una versión biográfica dada. No se trata, sin embargo, de un trabajo que se proyecta sobre una biografía en particular - de las varias que sobre Torres Bodet existen, aunque estas sean consultadas para construir su vida-, sino, en todo caso, de una aproximación que vierte una lectura de sexogénero-cultura sobre cierta reconstrucción de una vida, la de Torres Bodet, en un intento por radiografiarla como ejemplar - de ahí su carácter pedagógico-, y a la vez como una biografía que es también una suerte de cuerpo textual.

Asimismo, y como intentaremos mostrar, tampoco se trata de un trabajo sobre el Torres Bodet autor, en el sentido tradicional -en todo caso, importan definiciones más actuales y problemáticas de autoría-, y en cuanto a que no recurriremos a su obra publicada como material de trabajo. En esta línea, tampoco estamos proponiendo trabajar con el escritor como figura textual-literaria; incluso, no exclusivamente con la "persona" como la define Dominique Maingueneau (2015: 20) en tanto que individuo fuera de la creación literaria -o cultural-, pero entendemos que contextual a la misma.

\section{DEL GÉNERO AL BIOTEXTO PASANDO POR EL AUTOR Y NUEVAS HISTORIOGRAFÍAS}

Para Germán Labrador Méndez (2008), lo que él denomina biotextualidad aparece ahí en donde los lenguajes literarios, la identidad y la conducta establecen vínculos fuertes; los suficientes para que lo literario tenga consecuencias en el ámbito biográfico (s/p.). Esta definición nos sirve como un excelente punto de partida para denominar lo que antes hemos anunciado; la posibilidad de una biografía-vida como un cuerpo textual que se (re)construye a partir de lo vital, a la manera de movimientos, acciones y decisiones de vida; antecedentes sociales y familiares; a partir de lecturas, influencias y relaciones de amistad, entre otras diversas cuestiones. Esto, proponemos, entabla vínculos sólidos con una suerte de biotextualidad que a la larga puede reconstruirse -aquí y ahora, por ejemplo-, y que se distingue por ejercer un determinado poderío discursivo con influencia educativa y aleccionadora en un complejo sexocultural; digamos que el del México de finales del XIX y la primera mitad del XX.

\footnotetext{
${ }^{4}$ Cabe recordar que para Teresa de Laurentis, estas tecnologías “[...] tienen el poder de controlar el campo del significado social y, por ello, de producir, promover e implantar representaciones del género (de Laurentis, 1991: 259).
} 
Esta noción de texto sin duda se enmarca en el recorrido que va del estructuralismo a algunas propuestas posmodernas, y en un ámbito no exclusivamente literario. A este respecto, y sin necesidad de acometer una radiografía completa de la noción posmoderna de textualidad, ya en 1971 Roland Barthes, en el conocido ensayo "De la obra al texto", habla de la exigencia de un producto nuevo, el texto. Este, frente a la obra, que "ocupa una porción del espacio de los libros", es un campo metodológico (1994: 75). Para el francés esta distinción se establece con algo que dice Jaques Lacan: "la 'realidad' se muestra, lo 'real' se demuestra; al igual que la obra se ve (en las librerías, en los ficheros [...]) el texto se demuestra, se habla según ciertas reglas (o contra ciertas reglas); la obra se sostiene en la mano, el texto se sostiene en el lenguaje: sólo existe tomado en un discurso [...]". Y agrega más adelante: "El Texto sólo se experimenta en un trabajo, una producción" (75; las cursivas son del original).

Es esta idea de textualidad como resultado de una producción, de una cadena de cuestiones que perviven en el lenguaje -o en los lenguajes-, en el discurso, la que nos permite, de entrada, percibir la suma de ciertos testimonios de vida, tomados de aquí y de allá -de libros, de estudios, de archivos, de cartas, de apuntes, de hechos históricos, de biografías-, cercanos a lo que el mismo Barthes denominó biografemas (1971), como un cuerpo-texto al cual podemos acceder para acometer una serie de lecturas interesadas, en este caso, por prácticas sexoculturales y su función educativa. Esta idea móvil de lo textual -que atraviesa obras; varias obras, dice Barthes (1994: 75) - materializa más claramente su función ahí en donde el francés expresa que su lógica no es comprensiva, sino metonímica, ya que trabaja con asociaciones, contigüidades y acumulaciones; y "[...] coincide con una liberación de la energía simbólica" (76). De ahí que "El Texto [sea] plural", y lo que perciba lo haga como una "pluralidad estereográfica" que procede de sustancias y planos heterogéneos creando una combinatoria única (77; cursivas del original). Finalmente, dice, en el texto hay una reversión de la obra sobre la vida; y es ahí en donde la palabra "biografía" toma un nuevo sentido "fuerte", etimológico (79).

Con esta idea de biografía, que es separada de la fijación del lenguaje escrito, de la labor cuidadosa del biógrafo que contrasta los datos y los testimonios, y los valida -porque es un texto histórico lo que busca-, podemos esbozar la reconstrucción biográfica, en este caso de Torres Bodet, como una suerte de biotexto que cumple con una función con carácter historiográfico, y por ende formativo y educativo. En este nivel, si llevamos la idea de una versión biográfica múltiple como material biotextual, habría que buscar su carácter de historiografía educativa -en su contexto pero también hacia el presente - en lo que desde la historia ha dado en llamarse "el giro lingüístico" en algunas de sus manifestaciones más destacadas.

Así, y en un rápido esbozo, proponemos acceder al biotexto de Torres Bodet como un documento histórico -múltiple y no homogéneo- en primer lugar bajo algunas de las definiciones que surgen tras el ya clásico Metahistory, de Hayden White, publicado en 1973. El punto de aproximación que White innova en este trabajo es el de un acercamiento a los discursos históricos clasificados como tropos. Desde esta percepción retórica del habla de lo histórico Hayden argumenta cómo lo importante de estos radica no en los acontecimientos que se describen, sino en cómo lo hacen. Y para esto había que tomar en cuenta, principalmente, la historia de la política occidental, por supuesto, pero sobre todo el contexto social relevante -en el momento- y la historia de los modos de producción. En resumen, la propuesta de White en 
cuanto a que lo que se estudia en historia no son los hechos, sino discursos construidos sobre estos, en función de reglas retóricas y de un marco histórico, cultural y semántico siempre cambiante (Ríos, 2009: 107), permite mostrar la pertinencia de una recuperación de una vida "ejemplar" en un sentido no ya marcado por los hechos destacados, como ejemplos o actos aleccionadores por su contenido moral, religioso o de transformación social, sino más por el contexto en el que las acciones, movimientos y decisiones operan. Y así también, en cuanto a los sentidos y mensajes que circulan desde y alrededor de la figura educativa que se toma como ejemplo. El trabajo de White provoca una renovación en el ámbito historiográfico, de ahí que Lawrence Stone, en 1979, en un celebrado artículo diera el paso definitivo para considerar que la historiografía occidental funcionaba como una narración (Ríos, 2009: 108). En lo que aquí nos interesa, se trata de concebir a un determinado cuerpo narrativo como un texto que adquiere sentido como tal a la hora de ser ordenado cronológicamente como si de un relato de ficción se tratara.

En la línea de ambos aparece el conocido trabajo de Michel de Certeau, La escritura de la historia (1978), suma de la deconstrucción al giro de la lengua en la historiografía. Así, y a la manera en la que Lacan y Derrida establecen sus premisas, para el jesuita francés la historiografía es un discurso sobre "el otro" (Ríos, 2009: 109); y es una división que se establece entre el presente desde el que se escribe y el pasado sobre el que se escribe (de Certeau, 1993: 17). El pasado, entonces, es subjetivo y es una suerte de respuesta que cada autor se hace desde su propio presente. A este respecto, supongamos que la pregunta que queremos hacer sobre el pasado mexicano en términos de la incidencia que tienen figuras variadas, y que desde determinados campos actúan a su vez sobre una diversidad de esferas, en este caso es sobre la educación -de su práctica social y no sólo de su institucionalización- como constructo sexogenérico. Para de Certeau, así, lo histórico y su escritura -la historiografía - configuran una suerte de relato que está ligado al lugar de producción, a un contexto socioeconómico, político y cultural, y desde el cual se genera una determinada ideología, así como valores específicos, como nos recuerda Martín Ríos (2009: 110). Pero esta suerte de textualidad (histórica) es sobre todo una práctica; es un proceso de/en construcción.

Pensemos, a este respecto, qué pasaría si este proceso lo buscamos no en una escritura que se entrega como terminada por un autor - una biografía como "obra" en términos de Barthes-, sino que se construye y reconstruye sin cesar dependiendo del lugar desde el que se reescribe. La práctica de dicho biotexto se establecería en sentidos múltiples; a partir de los acontecimientos, hechos, movimientos y expresiones textuales del propio Bodet, tanto como hombre mexicano social y cultural de su tiempo, como hombre-varón, pero a la vez como figura pública de una misión educativa a la vez formal e informal. Esta práctica pedagógica estaría mediada por una ideología, una noción de cultura, y por la defensa y confección de un sistema sexo/género ideal; pero también por la validación y defensa de dichos sistemas desde espacios de masculinidad homosocial letrada. Entre dichos espacios, (re)conocidos en la historia cultural y literaria a través de revistas, ateneos, manifiestos o agrupaciones, sin duda destacan los que se engendran desde la autoría. Es decir, Torres Bodet, como hombre letrado todo terreno, se labró un lugar en la historia como un autor, al igual que muchos de sus congéneres. Sobre las estrategias homosociales de 
algunos de estos hablaremos lo suficiente en este trabajo, por ello ahora quizá ahora valga la pena relacionar la idea de biotextualidad con la del autor, la autoría y sus posibilidades.

A este respecto, resulta difícil imaginar a Torres Bodet más a allá o fuera de la idea de autor, si bien, dentro de los intelectuales de su tiempo, y junto con Los Contemporáneos, es el que posee, acaso, una más reconocida existencia como figura pública; es decir, como personaje de la vida cultural y política mexicana. Así también como educador de la nación, en una biografía que se solapa y entrecruza con la de, por lo menos, otros dos autores, personajes y educadores: Sierra y Vasconcelos. De hecho, en una trama nacional de poderes masculinos, Torres Bodet hereda las instituciones físicas y culturales de tejido homosocial creadas y dirigidas por estos: la Escuela Nacional Preparatoria, la Secretaría de Educación Pública, etc. Por otra parte, sin embargo, la dificultad de separar a un Torres Bodet idealizado como personaje nacional y de la historia del nombre que firma libros, del escritor y del poeta - de autor en un sentido amplio pero reconocible - nos sirve para perfilar una noción de biotextualidad.

Así, si como nos recuerdan Aina Pérez y Meri Torras (2015) en la introducción a un dossier que entrecruza la noción de autor con la de textualidad y cuerpo ${ }^{5}$, la idea de autor se ha revelado como esencial para "[...] dar cuenta del funcionamiento del texto en un sentido amplio, es decir, entendiendo como texto todos aquellos elementos que contribuyen a la producción de un sentido histórica y socialmente situado" (2). Y a su vez la figura autorial se teoriza en sí misma como textual, lo que es "[...] como un corpus conformado por un conjunto de textos heterogéneos: biográficos, académicos, visuales, autográficos, etc.” (2), podemos pensar que la vida de un personaje ejemplar en ámbitos de marcado prestigio - de la cultura letrada, la educación, la diplomacia y las relaciones internacionales, por ejemplo-, si es que se reescribe como una suerte de textualidad múltiple, puede equiparse a esos fenómenos de variedad y dinamismo, como si se tratara del producto de una autoría reconocida o reconocible. En todo caso, proponemos que la biotextualidad, si bien no se concentra en el corpus específico, completo o reconocido de un autor, o no exclusivamente en su actividad como escritor, o como poeta -sea textual o contextual; vital o virtual-, sí que considera a la figura a la que propone acercarse un tanto a la manera de los "Estudios Autoriales"; es decir, "[...] mediante una complejización de la noción de autor que lo considera más allá de la realidad fáctica, como sujeto real, para retormarlo como producto textual e histórico (Pérez y Torras, 2015: 3). En esta línea, es fundamental retomar lo que desde esta suerte de estudios se suma como "puestas en escena" (3; cursivas del original).

Entrando un tanto más en la cuestión autoral, y siguiendo la introducción mencionada, podemos establecer, por ejemplo, cierta cercanía entre el biotexto y la manera en la que José-Luis Diaz (2007) considera a la autoría como un dispositivo identitario en el cual se superponen lo real, lo textual y lo imaginario (en Pérez y Torras, 2015: 6); y más allá de la discusión en clave lacaniana que podría establecerse, sobre todo ahí en donde, en voz del propio Diaz, es

[i]mposible pues aislar una instancia "real", social y biográfica, sin "construirla" más o menos inconscientemente en función de un imaginario. [...] Imposible igualmente aislar una instancia puramente textual desde que se constata que esta elección exclusivamente

\footnotetext{
${ }^{5}$ Se trata de la introducción al dossier: "La autoría a debate: textualizaciones del cuerpo-corpus” (Tropelías, 2015).
} 
formal en apariencia [...] está en correlación con una elección socio-profesional [...] y la elección de una identidad especular (Diaz en Pérez y Torras, 2015: 6, en nota).

En el biotexto esas dimensiones de lo que coloquialmente llamamos realidad, lo textual y su relación con un imaginario sociocultural determinado -aquí como sinónimo de cosmovisiónestán igualmente trenzadas. Y es en una reconstrucción, ciertamente acometida por un autor otro, cuyos puntos de unión y de fertilidad de sentido se materializan.

En esta línea, la posibilidad de lo biotextual funciona de forma similar a lo que Pérez y Torras traen a colación acerca de la propuesta del mismo Diaz del "escritor imaginario" (2015: 6; cursivas del original). Desde este se concibe a la instancia autoral como un mecano o un rompecabezas que es configurado tanto por los/las escritores/as a través de "escenografías autoriales" epocales y de carácter colectivo (6), lo que podría contener una fuerte carga de estrategia homosocial, por ejemplo. Pero también desde la recepción, espacio en donde la figura autorial se "(re)construye a través de un montaje móvil y cambiante de sus piezas: paratextos tales como prefacios, dedicatorias; manifiestos o escritos sobre otros escritores/as; biografías, críticas académicas y periodísticas; u (otros) textos culturales vinculados a la escenificación de la autoría" (6; cursivas del original). Es en esta suerte de biografemas $^{6}$ verbales, de hecho, en donde pensamos que lo biotextual se reconfigura con mayor solidez; en donde se materializa. Sólo que la tradicional textualidad de dichas expresiones no es más importante que la de movimientos geográficos y sociales, decisiones de vida, asistencia a un determinado colegio o, por decir algo, la adscripción en el caso que nos ocupa - a un modelo de hombría vigente en la época. En lo biotextual los mensajes escritos dejados por ahí significan tanto como los puntos determinantes, no verbales, que dan forma al mapa de una vida "ejemplar", así concebida por un sistema cultural, educativo o sexo/género. El punto en común más fértil con la noción de "escenografía autorial" de Diaz viene ahí en donde el "escritor imaginario" es producto de las elecciones del sujeto "real", de sus reconfiguraciones, del "remodelaje" que en vida o póstumante realiza el lector sobre él (6); o a partir de él, podemos agregar.

El biotexto, así, creemos que puede ser trabajado -analizado, interpretado, e incluso deconstruido- como ejemplo destacado de un proceso de producción, significación y autoría de historicismo determinado. Por ello la vida textual de Torres Bodet, concebida como un destacado constructo de práctica ejemplar y demostrable influencia en las definiciones de la vida mexicana -de sus hombres y mujeres-, se presenta a continuación desde un quehacer a su vez discursivo, narrativo y educativo; y por ende autorial. Esto es, en cuanto a una selección de acontecimientos con suficiente carga afectiva y efectiva a la hora de encarnar y reflejar un constructo sexocultural como discurso educativo sin precedentes.

\footnotetext{
${ }^{6}$ Sobre esos detalles o pliegues que dicen todo sobre una figura letrada, Barthes menciona: "Si yo fuera escritor, y estuviera muerto, ¡cómo me gustaría que mi vida se redujera, con la ayuda de un biógrafo amistoso y desenvuelto, a ciertos detalles, ciertos gustos, ciertas inflexiones, digamos 'biografemas', cuya distinción y movilidad pudieran viajar fuera de cualquier destino" (1971: 14).
} 

HISTORIOGRAFÍA

Más allá del comprobado papel aleccionador e incluso modelizante de la literatura, así como de otras expresiones culturales bien valoradas por las definiciones occidentales de civilización, en los procesos de conformación nacional decimonónica en jóvenes repúblicas como la mexicana, la cultura letrada, y desde una conformación amplia, actúa como instancia educativa, es decir, formadora y conformadora de subjetividades y conciencias; de ciudadanos -hombresy de mujeres - como contraparte de la ciudadanía-, que a su vez son metáforas de la casa, la familia, la patria y toda una serie de espacios de lo privado y lo público.

A este respecto, desde lo que se ha denominado "república literaria" como espacio privilegiado de una cultura masculina, aunque también a través de otra particular práctica sexocultural que desde ahí se construye, la del educador mexicano, un tipo determinado de figura letrada actúa entre discursos y mundos, llegando incluso -como otros tantos poetas, artistas y hombres de su tiempo- a convertir su vida en una suerte de manual educativo. Estos sujetos de género y letra y cultura ejercen sus labores no sólo desde la escritura y la prensa como artefactos privilegiados de cultura, sino a partir de la creación y consolidación de instituciones universidades, secretarías, centros- Pero también a partir de prácticas y decisiones de vida, ligadas casi siempre a la conformación de espacios y redes homosociales de masculinidad -clubes, talleres, grupos, logias - desde las que no sólo se mantienen y generan bienes culturales de patria, civilización y alta cultura, sino artefactos funcionales de educación social, cultural y de la vida cotidiana. Estos hombres, proponemos, como una suerte de discursos encarnados, a la vez proponen y reflejan sus propias existencias como biotextos educativos. Dicha biotextualidad con carácter performático/performativo no deja de ser un legado para la nación mexicana por venir, pero también una suerte de manual de educación sexogénerica de gran efectividad en el mundo que se construía en el momento. Esto porque, pensamos, la conformación del México moderno ha de partir de una redefinición y renegociación de los sexos, sus definiciones y prácticas -tanto de género como de corporalidad — bajo la estipulación de modos de hombría y feminidad; de nuevas versiones de caballeros y damas. Asimismo, de un ordenamiento de los espacios públicos y privados, y de la función aleccionadora de una diversidad de textualidades, incluidas las vidas letradas como ejemplares.

\footnotetext{
${ }^{7}$ Para una idea resignificadora de este término en el ámbito de la cultura letrada mexicana, ver Martínez Carrizales (2007). Ahora bien, pensando en el contexto mexicano y latinoamericano es imposible eludir la noción de ciudad letrada de Ángel Rama; ensayo publicado póstumamente (1996) y en el que el uruguayo adelanta el camino a los estudios culturales latinoamericanos. La audaz cartografía de Rama acerca de la configuración espacial y de sentido de las grandes urbes de la América postcolonial establece con vivaz claridad cómo la cultura letrada y sus avatares se inscriben en el poder; y cómo a su vez se perfeccionan las funciones de lo que dará en llamarse intelectuales latinoamericanos, suerte de paradójico crítico, funcionario y servidor del poder central -cuestión que en México adquiere tintes novelescos-; sin embargo, esta cuestión, al ser concebida desde una perspectiva un tanto más estructural y diacrónica, no da cuenta del todo de la especificidad de un momento dado en la historia de México en el que los sujetos hombres-varones se hacen con la cultura letrada, se construyen una imagen novedosa de hombría y desde ahí, a través de estrategias intelectuales sumadas a viejas técnicas de dominación de género, renuevan el dominio y control de espacios muy determinados. A este respecto, el libro de Carrizales ha sido de enorme ayuda; esto porque el investigador de la UAM se concentra con agudeza en los pliegues menos notorios de dicho proceso de profesionalización e identidad. Esos pliegues nosotros los releemos en clave de género y masculinidad.
} 
A este respecto, Leonardo Martínez Carrizales (2017) ha validado en un libro reciente un entrecruce de historias y disciplinas que provocan el entendimiento de dicha cultura letrada -la "influencia letrada" - "[...] como un conjunto de prácticas sociales que desborda completamente las fronteras de la bella literatura, y se derrama en los ámbitos de la educación, la política, el derecho, el lenguaje" (14; cursivas del original). Ahora bien, en lo que aquí nos preocupa, queremos recuperar su noción de perspectiva historiográfica, misma que en consonancia con el giro lingüístico de Hayden a de Certeau, no sólo asume modos sensibles a textualidades entre disciplinas y artefactos, sino que se interesa por el análisis de formas simbólicas, en este caso de "carácter letrado", por medio de las cuales se establece el pasado de acuerdo con los intereses y valores de una comunidad circunstanciada temporal y espacialmente (2017: 14). Dichas formas simbólicas, en el panorama de una cultura de "minorías letradas", como acertadamente las denomina este autor, son alimento básico del "orden social” decimonónico, en un marco temporal que en su deriva abarca hasta buena parte del siglo XX (14-15; cursivas del original). A decir verdad, la textualidad, a la vez escrita y vital, que muchos de estos miembros de la minoría letrada dejan como práctica cultural, alcanza su expresión máxima desde lo que Martínez Carrizales denota como "cultura retórica". Es en este plano en el que se configuran los llamados "hombres de letras" (2017: 20; cursivas del original). Y esta es una identidad histórica que Torres Bodet, ligado tanto a la línea de los poetas como de los educadores, no pudo sino heredar y emular en el siglo XX. "Identidad expresada constantemente en las autorrepresentaciones de este sujeto histórico, fuente de su legitimidad social y alimento de sus tradiciones culturales” (20).

En el citado trabajo sobre Tribunos letrados es la noción de lo retórico, como base de conocimiento y educación en un sentido amplio, la que articula un espacio híbrido de reflejo y generación de bienes culturales; sentido que es resumido en la voz de Alfonso Reyes para quien la retórica "[...] desempeñaba el papel de una enciclopedia del saber, un arte educativa [...]" (2017: 29; cursivas del original). En este caso, el arte retórico como esencia pensamos que no sólo es heredado por un Torres Bodet que desde sus jóvenes inicios se inscribe con ahínco a la minoría letrada, a su vez elitista; sino que, acaso, una vez profesionalizado el quehacer de dichos caballeros de las letras la lleva a un espacio sin precedentes que, curiosamente, la misma historiografía de lo simbólico ha desplazado a un extremo oculto. Este no es otro que el del destacado papel que estas figura creadoras toman en la re/negociación de un particular sistema sexogenérico, el del México moderno, conformado no desde sus bases, sino, precisamente, a partir de sus minorías. Estas, como bien ha visto Martínez Carrizales, son las que deliberan acerca de la organización tanto del sistema educativo como literario (20); también las que refuerzan redes masculinas de homosociabilidad desde las que se producen los sentidos de una nueva nación. A este respecto, la biotextualidad, en este caso desde, por y a partir de Torres Bodet, se configura desde poses, ideales y prácticas sexoculturales hasta llegar, tanto en escrituras formales como en cartas, notas, frases destacadas, y así también en acciones y movimientos "de vida", a conformar un ideal de mundo que surge de los gremios y asociaciones literarias, de los clubes y salones, deriva en puestos de renombrada influencia pública, se refuerza en un ámbito letrado -y privilegiado- de diplomacia e intercambio transnacional -como en el caso de Alfonso Reyes- y termina por cifrarse en los artefactos discursivos de la figura del educador, así como sus ensayos y discursos públicos. 
De ahí, entonces, que sea pertinente preguntar: ¿cómo se conforman en momentos muy específicos estas figuras de género, masculinidad y transnacionalidad? ¿De qué contextos negociados en términos de masculinidad surgen? ¿Y a qué tecnologías de género e instituciones homosociales se deben como hijos y padres de la cultura letrada? Y por tanto: ¿qué nociones de sexoeducación, de sexogénero y de sexocultura practican en espacios a la vez nacionales e internacionales?

Para responder, por lo menos parcialmente a estas cuestiones, cabe mencionar la importancia de concebir la masculinidad o las masculinidades como en un campo constante de pugna y tensión. Por ejemplo, la que surge ente los liberales moderados y los radicales durante el Porfiriato. O la que se da entre los "afeminados" Contemporáneos, y los ásperos y duros escritores posrevolucionarios de corte social en México, hacia la primera mitad del siglo XX, como se verá. Esta aproximación bien puede hacerse desde lo que el sociólogo australiano Bob Connell determinó bajo el concepto de masculinidad hegemónica (1995). Desde ahí es posible explicar la estructuración jerárquica de los distintos modelos masculinos bajo el patriarcado predominante -o un patriarcado específico- - y que se presenta como un modelo sustituible.

En todo caso, pensamos, se trata de tomar las pugnas entre versiones de masculinidad $-\mathrm{y}$ por tanto de tensión de género- como un eje estructurador de sentido y significados. Y desde ahí determinar, entre otras cuestiones, cómo es que se llegó a naturalizar al hombre de letras (varón) como una instancia de reflexión crítica, sea histórica o cultural, inocua o transparente, aunque en verdad fuera el protagonista en todas las esferas de poder, como bien recuerda Víctor Macías-Gonzáles. Para él, "[el hombre-varón es] esa parte del orden social tan poderosa cuya presencia no siempre se nombra" (2007, 55-56). Por ello hay que establecer historiografías.

Finalmente, la suma de las cuestiones anteriores configuran una práctica de lo que podríamos llamar "pedagogías masculinas"; a decir, dispositivos de representación, aleccionamiento y cultura -letrada y sexogenérica- que actúan como lecciones, como biotextos, y cuya función es dibujar a los y las personajes de la vida moderna en México.

\section{TORRES BODET, UN NIÑO DEL PORFIRIATO: EDUCACIÓN CULTURAL Y DE LA VIDA COTIDIANA}

Jaime Mario Torres Bodet nace en la Ciudad de México en 1902, en el seno de una familia europea que había migrado del Perú a México. En una ciudad de extremosas desigualdades heredadas de la Colonia viene al mundo formando parte de ese $8 \%$ de clases medias y altas. Y lo hace en una extensión de 8 kilómetros, rodeados de barrios marginales y arrabales, en donde el 91\% lo constituían mestizos e indígenas pobres (Zertuche, 2011: 19). A este respecto, cuando se habla de "minorías letradas" no sólo se está haciendo referencia a un modelo de sociedad liberal en el que diversas profesiones masculinas dictan una tejido social de fuerzas económicas y creadoras más o menos homogéneo, sino en el caso de México -y su capital— de principios del siglo XX, en verdad describe a una notoria minoría de sujetos letrados y económicos, más a menos atrincherados en un centro que recuerda a la geografía medieval, rodeado por la miseria.

En este contexto, y en la cumbre del Porfiriato -recordemos que Díaz es reelegido por quinta vez en 1900-, la infancia de Torres Bodet se desarrolla bajo un control estatal casi total de las instituciones y sus poderes fácticos. Ahí, valores nacionales como la disciplina, la paz y el 
desarrollo permean las consciencias de una mínima ciudadanía en proceso de confección. Como pilares de dicho sistema, reflejados sobre la minúscula pero reforzada burguesía, planean el positivismo y el darwinismo social (Zertuche, 2011: 19), ejercidos por una élite, la de los "Científicos". Ahí prácticamente todos son abogados, pues la vía más segura en México de acceder a los espacios de poder es estudiar leyes. El "licenciado" es el dispositivo de masculinidad, política y economía más eficaz. Dicha élite letrada se alía con los caciques regionales y las compañías extranjeras, y como recuerda Carlos Monsiváis, ahí: “[...] no se mueve una hoja del árbol sin la voluntad del Progreso" (2016: 45). En todo caso, lo económico, la industrialización y los proyectos educativos son vigilados por un grupúsculo de hombres bajo la sombra del legalismo (45).

En este contexto de rectores de la vida económica, social y cultural, el trabajo de Martínez Carrizales identifica un proceso de profesionalización en el que los letrados se distinguen por medio de la asimilación del poder retórico, redactando textos para hablar de sí mismos o de sus coetáneos, estableciendo, así, “[...] la elaboración de las pautas de la cultura según las cuales los autores determinaban su propia conducta, o bien la simbolización de las prácticas de la palabra elocuente y persuasiva que se identificaban como los atributos fundamentales del sujeto educado [...]" (2017: 22). Este influjo, que vendría desde el XIX, cifrado sobre todo en la escritura, para las primeras décadas del XX en jóvenes de clases privilegiadas se presenta no como una opción más entre un sistema de oficios, sino, pensamos, como el grado más elevado de expresión cultural, así como la versión más destacada de nuevos modelos de masculinidad (letrada).

En lo educativo, sin embargo, el 80\% de analfabetos contrasta con una capital que avanza hacia un ideal laico de poder que no sólo se negocia en las pugnas entre positivistas y liberales, sino en una amplia confección de sujetos y ciudadanos, por una parte desde los valores de lo nacional -la "religión de la patria", la llama Monsiváis (46)—, pero, y de forma destacada, en la cultura letrada y desde una renegociación de los sexos, sus definiciones, funciones y posibilidades. Esto, podemos decir, termina por moldear el estado de género mexicano, adaptado a ciertos ideales mundializantes, como el de la definición misma de civilidad u otra metáfora del régimen: la respetabilidad (46). Un pequeño Torres Bodet de 8 años asiste, poco antes del proceso revolucionario, a la corona de esta versión de proyecto nacional: las celebraciones del centenario de la Independencia; un carnaval de ideales, patria y caballeros de sombrero de copa y chistera, y damas con grandes sombreros y enaguas de fru-frús de seda. Una radiografía de la moda ideal de hombres y mujeres de principios de siglo en la Ciudad de México conlleva, sin duda, un espacio de organización del mundo público y privado al que también se dirigen otras fuerzas, como las de la élite de letrados, poetas, novelistas, pensadores, historiadores, ensayistas, directores de periódicos, artistas, músicos, teatristas, educadores y abogados. Un poco más tarde el poeta surge como una renombrada opción de cierta virilidad artística.

Volviendo a la infancia de Torres Bodet, y en términos de representaciones de género, esta pasa por una suerte de sublimación cifrada en lo burgués. Al niño y a la niña, como símbolos destacados del progreso, del bienestar y de una (nueva) pureza "natural” (del Castillo, 2004: 88), se les borran los signos biológicos y se les asigna una identidad de género infantil asexuada. En este mundo interior a las casonas del centro, la madre, como dispositivo sexopolítico con poderes renovados, administra las funciones sexoculturales de la formación cotidiana. El "ángel del 
hogar" y la "perfecta casada", dos tecnologías de género mayúsculas, en las minorías burguesas de México se mezclan y adquieren la misión de formar sujetos en sus primeros años. Los resultados dependerán, así, del espíritu y pedagogía de cada madre. El mismo Torres Bodet hablará de ello en un pasaje autobiográfico: "Mi madre cultivaba la pedagogía del estímulo, no de la sensación. Me alentaba en lo que ella creía bueno y valioso o justo. Ese aliento me alejaba insensiblemente de lo demás. Y me alejaba de lo demás con mayor eficacia que una serie de prohibiciones y de censuras. No restringió mi libertad. Le bastó guiarla" (Torres Bodet en Poniatowska, 2002, s/p).

De 1900 en adelante, las élites administrativas e intelectuales de México se encuentran inmersas en los debates y nuevas pautas de vida y consumo derivadas de las pugnas e instauración de versiones de liberalismo, así como de los avances de la industrialización promovidos por el Porfiriato. En términos de educación social e instrucción de la vida cotidiana, la separación de esferas entre lo público y lo privado, confeccionadas desde la magna negociación liberal, en términos políticos, y desde las lecciones de las minorías letradas en términos culturales y de masculinidad, se ve reforzadas por una maquinaría ficcional y de cultura popular de consumo. Unos, caballeros letrados -y sus mujeres-, se dejan ver frente a otros, hombres de los oficios manuales, de servicios y a los migrantes del campo -y sus mujeres-, en la cultura del escaparate, los afiches y el performance de género de la cultura popular.

A grandes rasgos, el ideal femenino y masculino, si bien presenta una serie de variaciones y matices, puede resumirse en una síntesis del periodo isabelino hispánico. Desde aquí se expresa que la fisiología de hombres y mujeres determina su mente, sus capacidades y sus sentimientos, marcándose así una diferencia insalvable (Peyrou, 2011: 150). De este modo, al hombre se le imagina como un individuo libre y racional, y destacado por su capacidad de iniciativa, acción y reflexión (Laqueur en Peyrou, 2011: 150). Por ello su lugar es la "esfera pública", y su misión en la vida es trabajar, producir y elaborar leyes. En el otro lado, la mujer es ese "otro" que confirma la individualidad del sujeto masculino (Scott en Peyrou, 2011: 150). Además, sus órganos sexuales, y su papel en la reproducción y lactancia la acercan a la naturaleza y conforman " [...] una psique dominada por la sensibilidad, las emociones y la moralidad"; su lugar es lo privado, el universo familiar y su principal labor la crianza de los hijos y el cuidado del hogar (2011: 150).

En un mundo de intenciones y reflejos multiplicados hacia el interior y exterior de la nación en ciernes, las clases medias promueven su propio acceso a las normas de conducta y consciencia de sí -la self-awareness burguesa - como un capital cultural redituable (MacíasGonzález, 2006). Entre estos materiales de educación para la vida, los manuales de urbanidad y buenas maneras, estudiados por Víctor Macías-González como densas tecnologías de género y masculinidad, acaso son los que acometen una mayor penetración a la hora de instaurar pautas de honra, moral y clase, además de las bases, en este caso masculinas, desde una codificación sin precedentes de las distintas maneras de ser hombre: “[...] inferiores y superiores, jóvenes y viejos, amos y servidumbre, padres e hijos, ricos y pobres, conocidos y extraños, hombres de mundo e ignorantes, civiles y militares [...]" (Macías-González, 2006: 268). Y podemos agregar, de acuerdo a la naciente cultura letrada: intelectuales, poetas y educadores.

Pero también, queremos insistir, los bienes simbólicos que terminan como ideales de consumo surgen de aquella cultura letrada que exporta sus reflejos a las vitrinas y textualidades 
cotidianas, acometiendo hondos procesos de instrucción para las diversas esferas de una vida social compleja y estratificada. En todo caso, el perfeccionamiento de determinada élites burguesas y aristócratas, como la de los caballeros letrados, hacia el siglo XX no hace sino acrecentar los límites entre clases de hombres y mujeres. Con esto se marca una diferencia con el pasado colonial, a pesar de la aparente división por castas, si no pensemos en la ágil movilidad que, por ejemplo, posee el protagonista de El Periquillo Sarniento (1816); un hombre capaz de navegar entre mundos sociales, raciales, dialectales y culturales, pero sobre todo de masculinidad. En el paso del XIX al XX, en todo caso, [...] las minorías letradas en el México independiente se originan gracias a un diseño nuevo de organización social, un nuevo trazo de los límites del entorno societario gracias al cual un sujeto percibe el mundo y lo configura su conciencia" (Martínez Carrizales, 2017: 33). Sólo que ese mundo tiene la medida del hombre como base, y establece una elitista "[...] demarcación de los círculos en los que los individuos entran en contacto entre sí, establecen relaciones perdurables y emprenden actividades colectivas" (33). El mismo trabajo, en términos del extremo oculto de género, nos da la pauta para comprender los ideales, poses y prácticas sexoculturales que bajo la forma de modelos de hombría, heredaron y renovaron Torres Bodet y otros ilustres jóvenes ateneístas. Este hombre letrado, para comenzar

[...] ya no se concibe a sí mismo sólo como miembro de una familia, el paisano de una comarca, el socio de un gabinete de abogados, el funcionario que desempeña diligentemente sus tareas en una oficina de gobierno, etc., sino como un sujeto que libremente razona, estudia y discute sus conclusiones con otros que, como él, ya han experimentado los hábitos de una cultura crítica (34).

Es decir, la cultura letrada rebasa las profesiones tradicionalmente masculinas, pero no el género como límite en sí. A su vez, no sólo la escritura y su circulación educan a los hombres en rangos y espacios más allá del privilegio letrado, sino una biotextualidad in situ, en permanente construcción, determina, instruye, forma y alecciona.

De este modo, la cultura de género en la que un joven Torres Bodet viene al mundo es el resultado de un trabajo masculinizante de todo un siglo. Ahí podemos considerar a El Periquillo como la primer gran tecnología homosocial masculina, y desde la cual se establece una estrategia para con los sujetos y sus cuerpos. Se trata de un conglomerado de redes de relaciones, acuerdos, parentescos y compadrazgos entre varones. Este proyecto, por más contradictorio que parezca (frente al liberalismo y sus promesas de equidad), consiste en reforzar los sentimientos y funciones de la diferencia racial, social, económica y de género para construir una nación cohesionada desde el empoderamiento letrado de la idea de si del criollo y del criollo-mestizo burgués como metonimia de normatividad. Esto entre ellos y para con las mujeres. El ciudadano y el individuo -con género masculino no solo gramatical, como veremos en muchos de los discursos filosóficos y educativos del siglo XX - representan la confección más elaborada del proceso de unificación nacional (1750-1921). 


\section{JUVENTUDES DE HOMOSOCIABILIDAD Y PEDAGOGÍAS MASCULINAS}

El proceso revolucionario, que un joven Torres Bodet vive desde las calles suntuosas del centro y las aulas de los espacios de instrucción restringidos a élites de nuevos caballeros culturales, trae un nuevo desorden de ideales y posibilidades masculinas. Con este, Torres Bodet y otros hombres de nación y letras tendrán que negociar, pero desde una política sexocultural heredada del Ateneo de la juventud y esos otros campos más restringidos de poder homosocial, privilegiados por el Estado entre 1900 y 1914. Estos son los que posibilitan su identidad y la de sus amigos cercanos. En estos espacios plenos de significado de cultura de sexogenérica

[...] las minorías letradas entran en contacto entre sí con base en los valores que le son más estimados; espacios regidos de acuerdo con los hábitos colectivos del nuevo actor histórico; espacios donde priman representaciones verbales e iconográficas, modos del discurso y vocablos que, si no del todo nuevos, emergen y se hacen notar con una claridad [...] suscitando nuevas pautas para las relaciones entre los seres humanos (Martínez Carrizales, 2017: 36).

Seres bumanos varones, hay que apuntar. Como acertadamente lo hace notar Martínez Carrizales, dentro de estos espacios destacan las asociaciones literarias, mismas que en el caso de Torres Bodet y sus contemporáneos desempeñan un rol esencial, pues su iniciación letrada va del poeta al educador, pasando por el diplomático.

Hacia 1913, un Torres Bodet en proceso de formación asiste a la Escuela Nacional Preparatoria en San Ildefonso. Viste todavía pantalones cortos y su madre lo acompaña hasta la Catedral (Zertuche, 2011: 30). Esta carga de género aún infantil no impide su inserción definitiva en la liga de grandes formadores. Para 1914 da a leer su primer poema a Enrique Fernández Granados; y es ferviente escucha de jóvenes pero pujantes profesores: Alberto Vázquez del Mercado, Manuel Toussaint y Antonio Castro Leal (31). En este espacio, un tímido y molestado Torres Bodet (por su gordura todavía infantil) comienza a desarrollarse y ganar un lugar en uno de los espacios más privilegiados por la lógica sexogenérica de las élites, el de las amistades apasionadas entre varones afines: Bernardo Ortiz de Montellano, José Gorostiza, Carlos Pellicer, Luis Garrido, entre otros. Estos nuevos caballeritos de las letras y el conocimiento muy pronto reflejan su haz de intenciones culturales hacia el Ateneo de la Juventud que Caso, Henríquez Ureña, Reyes y Vasconcelos habían integrado unos pocos años antes ${ }^{8}$. En términos de educación cultural e informal, ahí se consagra un retorno al humanismo, el cultivo de la cultura occidental, y se desarticula el sistema educativo positivista. Como poetas, gestores culturales, rectores de universidad, diplomáticos y otros tantos avatares de masculinidad, definen los contornos de la educación nacional, de la cultura y de las relaciones internacionales.

En los espacios de masculinidad, tanto educativos - como las aulas de la Escuela Nacional Preparatoria - como letrados, podemos imaginar a un joven poeta en proceso de formación, Torres Bodet, ensayando y dominando un arte también etiquetado por el sexo y el género; el de la

\footnotetext{
${ }^{8}$ Es imposible ignorar el trabajo de Susana Quintanilla, "Nosotros". La juventud del Ateneo de México (2008) en cuanto al hondo sentido de intimidad entre varones auto percibidos como iguales y letrados -ese "nosotros"-, el funcionamiento de las relaciones maestro-alumno, y la diversidad de éticas y estéticas que se pusieron en marcha en la juventud del Ateneo.
} 
conversación. Del XIX a las primeras décadas del XX podemos visualizar en las geografías blindadas por los tejidos homosociales a

[...] sujetos que comparecen entre sí libremente, convencidos de los beneficios de la lectura reflexiva y el intercambio de ideas, orgullosos de los libros que leen y de las tradiciones intelectuales en las que han decidido ameritarse, bien dispuestos para cumplir con las leyes de un trato paritario, hábiles en el manejo del lenguaje y en la construcción de discursos de todo tipo, dueños de sus propias palabras (Martínez Carrizales, 2017; las cursivas son nuestras).

Aunque dicha paridad, en todo caso, estaría sujeta no sólo por el sexo y su representación genérica -la de un varón letrado-, sino por la raza y la clase.

De esta época, en el sentido homenaje que varios de sus amigos y maestros le dedican en 1965, titulado Jaime Torres Bodet en quince semblanzas, a Alfonso Caso, dentro de los diversos avatares de su figura de hombre letrado -el poeta, el escritor, el impulsor de las artes, el diplomático, el educador, el humanista, el instructor de México...—, le toca hablar de "El hombre y el amigo". Ahí, en un afectuoso texto que toma como punto de partida el encuentro del maestro con el alumno en las aulas de la Escuela Nacional Preparatoria, Caso resume el núcleo de admiración por tan aventajado aprendiz: "Lo que siempre admiré en Jaime fueron no sólo sus cualidades intelectuales, sino lo que creo es en él esencial: su vocación para enaltecer al ser humano y protegerlo de todo aquello que pueda menoscabarlo y su constante fe, que nunca ha flaqueado, en la redención del hombre por la educación" (1965: 16). Como homenaje, lo que el filósofo está destacando del poeta-educador no es otra cosa que la base de una normatividad de género, aunque, ciertamente, amparada bajo el cobijo de otros manuales del complejo del saber mexicano y universal - del humanismo, de la civilidad, de la ciudadanía...-, aunque igualmente cifrados en clave masculina. En este sentido, para Judith Butler, en cuanto al "reglamento del género", "[l] a norma rige la inteligibilidad, permite que ciertos tipos de prácticas y acciones sean reconocibles como tales imponiendo una red de inteligibilidad sobre lo social y definiendo los parámetros de lo que aparecerá y no aparecerá dentro de la esfera social” (2007: 69). Podemos pensar, con esto, que la figura cultural y letrada restante de la suma entre la textualidad y la vida de Torres Bodet, a su vez vista desde los lentes de otros hombres, igualmente ilustres, no sólo inscribe las normas del "Hombre" categórico del conocimiento en un reglamento de la cultura nacional, sino en las lecciones normativas de un sistema particular, de ahí que Castro vea en Torres Bodet un "ideal" con "[...] una inteligencia superior y una amplia y vigorosa cultura". Es un $\mathrm{H}$ /hombre, pues, con "logros espectaculares" y cuyos ideales humanistas se confeccionan no sólo la educación nacional, sino la "cultura mundial" - en referencia a su periodo como director de la UNESCO_- (1965: 16). Este Hombre como norma de lo social, de lo cultural, de lo educativo y de la expresión más sublime de la civilización, el humanismo, se sitúa en una normatividad que cita las leyes de un sistema binario, el de la diferencia sexual, estipulando una muy particular -y creadora - definición de género. Apelar constantemente a ese "Hombre" establece una normatividad como "[...] un discurso restrictivo de género que insist[e] en el binario del hombre y la mujer como la forma exclusiva; [como] una operación reguladora de poder que naturaliza el caso hegemónico y reduce la posibilidad de pensar en su alteración" (Butler, 2007: 70-71). Dicho campo hegemónico no es otro que el del Hombre que engendra al hombre de la 
letra, la voz y la educación; y este, a su vez, es el padre, "el instructor" del hombre -varóncomún: el marido, el maestro, el hijo, el alumno. Alterar este sistema de parentescos masculinos es conducir la vida a la barbarie, a la crisis, de ahí la importancia irreprochable de un reglamento letrado de género.

En este campo de normas, Caso tiene muy claro cuál es la estrategia, que ya ha sido reiteradamente comprobada, en cuanto a su efectividad, por lo menos desde Fernández de Lizardi: la amistad apasionada. Así, agrega: "Y por esta razón es también un gran amigo, porque su amistad está fundada en la comprensión y en la simpatía [...]”. La compresión y la simpatía, dos pasos esenciales de una hermenéutica de hombres que "[...] no es simplemente una conciencia de solidaridad intelectual, sino que va más allá y busca la conexión con lo más auténtico y más profundo del espíritu” (1965: 16-17).

Un poco más tarde, otro factor que promueve la conformación de Torres Bodet como un novedoso tropo de la masculinidad intelectual es la propuesta de renovación del funcionariado mexicano desde los "nuevos jóvenes". En este periodo "[1]a juventud tuvo connotaciones morales, estéticas y simbólicas propias, que depositaban en el Joven los más generosos ideales humanos: es el activo, el audaz, el ambicioso, el experimentador, el capaz de las grandes emociones, el creador” (Blanco, 1996: 163). Como artefacto político de género, el “joven” varón es un constructo promovido por el liberalismo burgués y el proyecto educativo nacional. Por ello su duración y etapa formativa es ampliada y reforzada. La Escuela Nacional Preparatoria, la Escuela de Jurisprudencia - en la que Torres Bodet se inscribe en 1920-, y los mundos circundantes de ateneos, clubs, cafés y grupos -y sus manifiestos- conforman los escenarios para la práctica de este estadio al que no solo se le descubren funciones de validación de clase y raza, sino de transformación nacional más allá de los lindes de la capital. Este es un nuevo ideal de masculinidad que adquiere enorme calado frente a intelectuales-formadores y conservadores de décadas anteriores: José Roa Bárcena, Ignacio. M. Altamirano, o José Tomás Pérez de Cuellar, por ejemplo; y quienes vieron en las juventudes emergentes una amenaza al imperio masculinizante mexicano. De este modo, el antiguo "cachetitos de manzana", como llamaban a Torres Bodet sus compañeros de preparatoria, se transforma en un elegante caballero con traje High Life o de El Palacio de Hierro (Zertuche, 2011: 40).

Poco después, y como un representante bastante destacado de la juventud letrada, pasa de ser el joven y eficiente secretario de la Escuela Nacional Preparatoria a ser el secretario de su admirado José Vasconcelos en la rectoría de la Universidad Nacional, en 1921, a los 19 años. La figura de Vasconcelos, sus escritos, acciones y decisiones políticas; todas sus creaciones educativas en un amplio ámbito: escuelas, bibliotecas y sus "misiones culturales" transforman el ideal ético y cultural de Torres Bodet. El paso de Vasconcelos de la universidad a la Secretaría de Educación Pública no hace sino dinamizar su vida pública. En este transcurso, termina, después de 1922, en la Dirección de Bibliotecas.

La profesionalización literaria de Torres Bodet va en paralelo a su experiencia en cargos públicos de confianza. El periodo de crisis revolucionario, si bien complica la publicación y circulaciones de bienes culturales, acaso vivifica los grupos y sus ideas, y las no siempre claras relaciones entre modernidad y vanguardia. Estas relaciones paradójicas pueden cifrarse en 
diversas revistas. En muchas de estas también colaboraron autores españoles e hispanoamericanos afincados en Madrid, París y otras capitales, procurando así una dinámica red transatlántica de intercambio de saberes. En este entramado se renegociaron muchas de las identidades nacionales, de clase y de género en un marco internacional. Aquí vuelven a destacar, por supuesto, las definiciones de los hombres letrados, así como de una todavía en formación idea del intelectual y del ciudadano. Categorías genéricas que excluyen abiertamente a la mujer, como sucede en los discursos educativos, proyectados en y desde un marco transnacional, del propio Torres Bodet.

Entre dichas publicaciones destacan el semanario Pegaso, fundado en 1917 por González Martínez, López Velarde y Efrén Rebolledo, en donde se incluyen las colaboraciones de unos jóvenes Carlos Pellicer o Torres Bodet. También la Revista Nueva, que en 1919 dirigen José Gorostiza y Enrique González Rojo (Zertuche, 2011: 49). O de 1920 a 1923 la revista mensual México Moderno, también de González Martínez, en donde se unen los ateneístas, y los recientes Gorostiza y Torres Bodet como críticos y receptores de la literatura francesa: André Gide, Marcel Proust, Jean Cocteau, Paul Valéry, etc. Destaca, en 1922, y bajo el patrocinio de Vasconcelos, la aparición de La Falange (1933), cuyo alcance es continental y pretende, más allá de reglas y razas, unir las voces de los hombres (y de algunas pocas mujeres) de América. Participan democráticamente poetas, pintores, muralistas en uno y otro extremo del espectro ideológico, si bien, en términos de ideales de masculinidad después habrá un rompimiento.

Esta nueva camada de caballeros de las letras no sólo se configura como ideal de masculinidad letrada al interior de los espacios de homosociabilidad, sino que practican sus versiones de sexocultura en banquetes, funciones de ópera y teatro, concursos y entregas de premios, etc. Tanto en el mundo privado como en el público, los nuevos "árbitros de la elegancia" (Macías-González, 2006) hacen gala de su modernidad y superioridad de clase. Esta ya no estaba sólo basada en la acumulación-circulación de capital, sino en poses, sensibilidades, mentalidades y lecciones de carne y hueso frente a los ideales de masculinidad elitista que antes había en revistas, aparadores o salones privados. Si como han visto Macías-González o González Romero (2015), la performance de género masculina pasaba por lo literario (culto o popular), aunque para un grupo muy reducido de lectores $-\mathrm{y}$, aquí sí, muchas lectoras-, casi todos burgueses y aristócratas, los nacientes Contemporáneos instruyen no sólo desde sus textos, sino desde una notoria presencia social.

En el ámbito de la cultura, Torres Bodet, Ortiz de Montellano y Gorostiza promueven la conformación de un Nuevo Ateneo de la Juventud, y si bien esta asociación que buscaba renovar los bríos poéticos de las relaciones masculinas del antiguo Ateneo no pasó a mayores, si lo hizo el más famoso de los grupos literarios de México; algo así como el clímax de una versión de cultura homosocial mexicana entre los nacidos en el Porfiriato. Ahora, de cara al grupo de los ateneístas, ¿qué recuperaban los jóvenes de los antiguos caballeros de las letras? Como base de una sexocultura masculina podemos pensar que el impulso vital -"el conocimiento como acción, la inteligencia como sensibilidad y la moral como estética", como clamaba Jorge Cuesta" (Monsiváis, 2016: 35). Así también lo que Monsiváis llama la "revolución moral", que se organiza alrededor de la idea de "el héroe" (de Maurice Blanchot a Alfonso Reyes, y de ahí a José Enrique Rodó y otros latinoamericanistas) (36). El héroe no es otro que el poeta que de los 
clásicos de Occidente pasa a los valores del sujeto masculino liberal. Otra cuestión es la idea de moral como fuerza civilizatoria en la que los hombres-poetas son casi soldados. Muchas de estas ideas las recuperará Torres Bodet no sólo en sus poemas, sino, sobre todo, en sus textos y discursos sobre educación en el ámbito bélico europeo. Sin embargo, en el otro extremo de la red homosocial mexicana están los escritores y artistas ligados a la revolución y sus temáticas regionalistas. Estos, frente a los afectados, cosmopolitas y calificados como homosexuales -los Contemporáneos-, clamaron un retorno a una idea de cultura viril en México. Con un ideal paternalista y patriarcal, y desde diversos frentes que retoman a los "oprimidos" como el centro de la representación del hombre mexicano. Así, indios, campesinos y obreros trazan un mapa nuevo de relaciones con los señores: militares, amos, licenciados y escritores.

Ahora bien, el impacto nacional de Torres Bodet y los caballeritos letrados se da desde la publicación de libros de poesía; y a esto reaccionan algunos intelectuales de generaciones anteriores, como Julio Jiménez Rueda, quien dicta la conocida conferencia: "El afeminamiento de la literatura mexicana" (1928). Por su parte, Maples Arce (y los estridentistas) niegan la posibilidad de tal construcción: los llaman "grupo sin grupo" (Villaurrutia, 1924; cursivas del original), pues no creen que tengan temas, afinidades ni una propuesta como tal -mas que una puesta en duda de la virilidad nacional- En la base de estas críticas, como lo han mostrado Mckee Irwin (2015) o del Toro (2015), estaba el repudio a una posibilidad masculina pero homosexual, temida desde una cultura igualmente masculina aunque sobreviviente del Antiguo Régimen, y organizada en los férreos ligamentos homosociales centrados en los partidos políticos y sus ideologías en proceso de transformación.

En cuanto al Torres Bodet poeta, en el ya mencionado volumen en el que se le rinde homenaje, Rafael Solana expresa cómo la poesía “[...] fue la primera, y tal vez la más alta y permanente, de las vocaciones de Jaime Torres Bodet [...]"; y que "[...] cuando se le mencione dentro de un siglo se diga 'el poeta Torres Bodet', y luego se agregue que fue además crítico, prosista, orador, ministro. Don Justo Sierra también fue todo eso; pero como poeta fue pequeño [...]" (1965: 27). Con la petición de Solana de remarcar al poeta antes que a los otros avatares parece que se está realizando algo más que la celebración de la figura del aludido como tal por encima de sus otras identidades, o de la poesía como espacio destacado de consagración de la vida artística del "hombre", si no, y con la mención de Justo Sierra, algo así como la confirmación de una saga de creadores de las letras que no hacen sino superar a sus maestros. Como pedagogía de género, la historia de la cultura se sitúa bien en el discurso del aprendizaje.

Para Solana, Torres Bodet, Carlos Pellicer y José Gorostiza son los

tres nombres que estaban destinados a llenar las dos o tres décadas siguientes, y a brillar en lo más alto, uno u otro de ellos, según las preferencias de cada lector, como cumbres de la poesía mexicana dentro de una generación brillantísima que los historiadores literarios llaman de “Contemporáneos”” (1965: 28).

Nombres-hombres-poetas que en el clímax del reglamento de género pueden sentirse como iguales, y escribir para sus lectores, pues la poesía mexicana es cosa de varones. Para François Ewald la norma -de género- emerge conceptualmente no sólo "[...] como una variedad particular de reglas, sino también como una manera de producirlas y como un principio de valoración (en 
Butler, 2007: 79; cursivas del original). La cultura letrada masculina, como dispositivo de reglamentación, produce sus normas en los límites de lo homosocial y bajo la retórica de la valoración entre iguales. Y esto define a la "persona" del mundo mexicano, la cual es de sexo masculino -aunque su escritura e identidad renueven las expresiones de género de lo masculino en sí-. Foucault asegura, en este contexto, que la disciplina "produce" individuos, y para Butler, con esto "[...] no sólo quiere decir que el discurso disciplinario los dirige y los utiliza, sino también que activamente los constituye" (2007: 80; cursivas del original). A este respecto, la disciplina literaria es innegable en su papel creador de nación y ciudadanía.

Ahora, en cuanto a las estrechas relaciones entre varones letrados, más allá de la conocida (y atacada) homosexualidad de Villaurrutia, Pellicer, Nandino, Novo..., una cuestión que sí habita con fuerza en la práctica de género de Torres Bodet son las antes mencionadas amistades apasionadas. Se trata de una honda estrategia homosocial descrita como una "[...] amistad cuyo alto grado de intimidad se afirmaba mediante el intercambio de ideas y opiniones, creando un lazo emocional fuerte y un compañerismo estrecho" (Macías-González, 2008: 21). De la Colonia al México posrevolucionario, la élite mexicana de hombres empleaba vínculos interpersonales mediante apasionados lazos afectivos; una suerte de "sabiduría social" de varones sin precedentes (21). Una carta de Josefina Suárez Montañés, su esposa, a Torres Bodet, ya en el periodo internacional, da cuenta de este hecho, molesto desde la posición de la "compañera". Se refiere a la estrecha relación ente su marido y Bernardo Ortíz de Montellano, otro de los Contemporáneos:

[...] hoy [...] me dieron la mala noticia de que sale para Nueva York Bernardo [...] seguramente va a recibirte a la estación y tú estarás más contento. ¿Para qué puedo hacerte yo falta? [...] No puedo dormir [...] lo que más me inquieta es saber por qué te preocupas tanto por Bernardo, nunca creí que lo quisieras tanto, al grado de que no puedas vivir sin él. Estoy tan celosa de Bernardo (en Zertuche, 2011: 67).

En el mundo de afectos personales, en 1922 Torres Bodet había conocido a Josefina. Se trata de una mujer poco representativa para la época, pues vivía sola y estudiaba piano e inglés. La relación con la que será su "compañera" -según la definición de la época, reforzada por el educador, y como ella misma pasará a la superficie biotextual — ha quedado cifrada en las cartas de épocas diferentes. Torres Bodet, como hombre letrado de su tiempo, manifiesta muchas de sus pasiones en misivas, tanto a su mujer como a sus amigos. A Josefina, ya en el 34, y tras la primer aventura europea, le escribe: “Te amo como en nuestros años más juveniles, pero con más ternura todavía como a mi novia, como a mi hermana, como a mi hija [...] pues me has querido como amante, me has consolado como mi hermana y me has colmado de alegría como una hija" (en Zertuche, 2011: 67).

\section{UN HOMBRE INTERNACIONAL. POSES, IDEALES Y PRÁCTICAS BIOTEXTUALES}

Torres Bodet, proponemos, como joven vivo de su tiempo, tendrá que esperar para construir un ideal a la vez nacional e internacional del hombre -tanto genérico como del varón modernotras sus estancias en Madrid, París, Bruselas, La Haya o Buenos Aires. Dichos modelos, que si bien se habían venido fraguando en una intensa juventud como intelectual y poeta en México, en donde encontrarán un espacio pleno será en los escenarios de comunicación institucional, en sus 
cargos públicos y en la práctica diplomática internacional. Se trata, como veremos, de la imagen del hombre de la historia y del conocimiento; del hombre letrado y de la poesía; del hombre educador y del educado; del hombre del pueblo en proceso de instrucción y ciudadanía; del hombre como Hombre y como medida de la historia, la política, la nación y las letras. Es decir, una serie de avatares de una masculinidad-saber en la que no hay pruebas -ni de marcas lingüísticas, textuales ni sexuales - de que hubiera cabida para la mujer como algo más que no resultara ser una suerte de complemento dentro de una dialéctica asimétrica frente al sujeto masculino. Un "Otro", en términos de Simone de Beauvior (en Butler, 2007: 65). Así tampoco, pensamos, habría espacio para la acción letrada para los hombres en espacios fuera de los lindes de la instrucción formal -o de la cultura letrada en sí-.

Volviendo a Torres Bodet, desde una breve genealogía, proponemos que su pronta militancia en una pequeña pero intensa cultura burguesa letrada, así como su participación en los Contemporáneos con la idea de "libertad" como eje, lo marcan como un tipo determinado de subjetividad masculina mexicana que puede proyectarse en lo transnacional. Torres Bodet y sus amigos apasionados representan un ideal de hombre letrado, culto, refinado y con miras al mundo exterior; sobre todo Europa. Son caballeros de clases medias y altas que comparten educación en centros urbanos, así como en novedosos espacios de instrucción homosocial, como hemos visto, y en donde destaca la Escuela Nacional Preparatoria. A ellos el proceso revolucionario más que afectarles les beneficia en términos de consolidación de ese nuevo modelo de masculinidad, cultura y consumo. Son lectores, críticos y con convicciones plenamente modernas, y por ello crean redes de lectura y construcción cultural mediante publicaciones que buscan forjar ideales literarios y filosóficos transatlánticos. Aquí destacan, por ejemplo, los circuitos de comunicación epistolar, ya que en dichas cartas puede cifrarse la negociación de ideales, así como la posición que distintas capitales del mundo fueron adquiriendo: París -el centro del mundo hispánico, a pesar del francés-, Madrid -reflejo de una versión de hispanoamericanismo—, Buenos Aires - el centro más vibrante de una literatura original—, o la Ciudad de México, geografía pujante de cultura sexogénerica que Torres Bodet encarna biotextualmente. Y también las capitales de la cooperación internacional del mundo de entreguerras: Bruselas, La Haya, Nueva York. Torres Bodet vivirá como agregado y diplomático en casis todas estas, acaso siguiéndole los pasos a su admirado Alfonso Reyes. Desde todos estos destinos, en los que vivió con sus dos mujeres -su madre y su esposa- se carteó con amigos y colegas, presentándose la carta como un espacio textual de intimidad y negociación homosocial en un nuevo mundo en el que las fronteras comienzan a diluirse. Es así que se configuran nuevos signos de un pensamiento de aires transnacionales, y esto en relación con las diversas élites intelectuales de los lugares en los que vive.

Hacia finales de la década de los años 20, México quiere reforzar su posición internacional. Los requisitos para acceder a estos puestos incluyen duros exámenes sobre historia y geografía del país y su actualidad, así como de cultura internacional, sobre todo europea y francesa. Asimismo, hablar más de una lengua extranjera. Torres Bodet se prepara con ahínco para esta cuestión; el francés lo dominaba gracias a su madre, que era bilingüe y nunca había abandonado los aires galos, y por los orígenes del padre leía y podía sostener conversaciones en italiano. En todo caso, tuvo que prepararse en contabilidad y derecho internacional, cosa que resultó sencilla. 
Para mediados de 1929 ya es el tercer secretario en Madrid y hacia 1931 asciende rápidamente y ya es segundo secretario. En este contexto, vive con intensidad la efervescencia de la Segunda República (Zertuche, 2011: 66), y en misivas a su admirado Reyes le cuenta que sufre el clima caluroso tan terrible de Madrid pero disfruta con sus congéneres poetas, pensadores e intelectuales: Pedro Salinas, Benjamín Jarnés, Melchor Fernández Almagro, Claudio de la Torre, Juan José Domechina, Max Aub y Ramón del Valle Inclán. Estos constituyen el grupo de interlocutores varones que se reúnen en un espacio homosocial de gran importancia, la peña literaria en el Café Regina. Se trata de uno de los escenarios, a medio camino entre lo público y lo privado, para las relaciones intelectuales de las élites letradas de la época. Estas redes masculinas, entre otras cosas, teorizan sobre el futuro del hombre - del poeta- desde el Modernismo y el ascenso de las letras hispanoamericanas en un nuevo orden mundial. También renegocian, desde la literatura, las definiciones de los sexos, los géneros y sus funciones en la España venida a menos como potencia imperial.

La experiencia madrileña duraría poco menos de dos años. Con enorme agrado recibe la noticia de que es trasladado a París y allá va con su madre y Josefina (2011: 69). En París trabaja con dos respetables revolucionarios mexicanos: Arturo J. Pani, cónsul general, Marte R. Goméz y el poeta estridentista: Luis Quintanilla (69). La vida parisina le fascina a la familia Torres Bodet. Las cartas de la época dan cuenta de una ávida vida cultural: museos, conciertos, cinematógrafo (69). Como lo había hecho en Ciudad de México o Madrid, entra en contacto con las élites intelectuales, sobre todo de hispanistas migrados.

En 1932 es trasladado temporalmente a La Haya como encargado de negocios. Ahí lleva una vida menos intensa que en París, pues sus labores implican hacer de interlocutor con las autoridades del reino, entablar relaciones con los representantes de los países amigos y autorizar y renovar visados (70). Al no dominar el idioma dedica el tiempo libre a escribir, y visitar museos y los alrededores. Para septiembre ya está de vuelta en París. Asiste con asombro, como todos los intelectuales de la época, a los desafortunados acontecimientos que van marcando la vida europea (70). En este contexto, Torres Bodet cumple con la definición que Sanz Roig (et al.) dan al mediador cultural, ahí en donde se presenta como un "[...] cultural actor active across linguistic, cultural and geographical borders, occupying strategic positions within large networks and acting as a carrier of cultural transfer" (2017: 67). De ahí que como hombre destacado de la mexicanidad haya acometido acciones culturales sin precedentes. En 1934, por ejemplo, es invitado por el Instituto de Estudios Hispánicos de la Sorbona para dar una conferencia sobre la poesía mexicana desde Sor Juana Inés de la Cruz hasta Ramón López Velarde (70-71). Más allá de la lengua o las fronteras nacionales, el punto de vista de Sanz Roig (et al.) insiste en los procesos de transferencia, en la superposición de roles y la transgresión de campos culturales (67). En esta normativa de cultura de género transnacional, el poeta es diplomático; el diplomático es traductor; el traductor es educador; el educador es conferenciante; y este es, de nuevo, poeta. Estas son, todas, versiones de identidad en las que el sujeto se trasviste de versiones de género legalizadas por biotextualidades masculinas.

En el verano de ese año recibe con tristeza una noticia; debe dejar París para trasladarse a Buenos Aires. A la República Argentina viajan sólo los esposos pues la madre decide regresar a México. Como sujeto "entre mundos" de la época, y más después de la experiencia parisina, 
Torres Bodet se considera un "europeo en América". Germina en él la idea de la superioridad francesa, así como el legado sin igual de sus pensadores y escritores (71). Esta posición radical comienza a transformarse en la estancia a Buenos Aires. Ahí, un sentido nuevo y móvil de mexicanidad comienza a Florecer en un Torres Bodet que entra en contacto con "otras versiones" de cultura letrada europea en América; de ideales de nación. Leopoldo Lugones, Jorge Luis Borges, Eduardo Maella, Ezequiel Martínez Estrada, Ricardo Molinari y Arturo Capdevila constituyen el nuevo grupo de varones letrados. Destaca, casi como una excepción, Norah Lange. Y la gran ausente en su interlocución transatlántica será Silvina Ocampo, con quien no coincide (78). Si en la apertura del tejido homosocial a la mujer Buenos Aires resultaba innovadora, Torres Bodet no parece reaccionar ante este hecho.

La experiencia bonaerense es corta pero intensa. Con el presidente Lázaro Cárdenas en el poder mexicano los Torres Bodet regresan a Francia. Para 1936, viviendo entre París y La Haya, el educador mexicano vive con temor el ascenso de Hitler y el ambiente Europeo (73). Él y otros tantos mediadores internacionales discuten desde sus trincheras discursivas las cuestiones de supremacía y segregación racial, así como las nuevas definiciones de lo imperial y lo nacional. En 1937 Lázaro Cárdenas lo designa a Bélgica; espacio privilegiado del momento europeo para comprender el conflicto. En 1938 es un fiel defensor en Europa de las políticas de corte social y nacional del presidente, como la expropiación de las compañías petroleras (74). Para 1939 vive con temor a los bombardeos y la precarización de la amada vida europea. En su regreso en barco a Nueva York, en donde zarpan desde Lisboa, Torres Bodet escribirá lo siguiente:

[...] todo un mundo vencido ya, antes de lo que los hechos lo derrotasen. Y un mundo vencido por la peor de las epidemias: la de la angustia. La Europa libre no había sido sólo desintegrada en la hora de la agresión. Había sido minada, durante años, por la indecisión de las democracias ante las fuerzas del fascismo y del comunismo, por su inercia frente a los sátrapas del chantaje internacional, por la indiferencia de las grandes potencias para los pueblos débiles y por su intolerancia ante los desplantes de un Hitler que se creyó Bonaparte y un Mussolini que se soñó Julio César (Torres Bodet, 1974: 228).

En 1940 regresa a México y decide quedarse, optando a una consejería del Servicio Exterior. En 1943 el presidente Ávila Camacho lo designa secretario de Educación Pública (lo es hasta 1946 cuando finaliza el sexenio). Del 1946 a 1948 se desempeñó como secretario de Relaciones exteriores. Finalmente, el clímax de la trayectoria universal del educador llega cuando es elegido como director general de la UNESCO (1948-1952).

Pedagogías masculinas. BioteXtualidad, el H/hOMBRe y los PERSONAJES DE LA VidA MODERNA

¿Pero qué ideal del hombre y de la masculinidad cifró el más internacional de los intelectuales-educadores mexicanos tras su interlocución transatlántica y tras su juvenil militancia en las minorías letradas de caballeros? Judith Butler estipula como un principio que "[...] es imposible separar el 'género' de las intersecciones políticas y culturales en las que constantemente se produce y mantiene" (2007: 49). De ahí que un posible ideal del hombre masculino en el educador pueda pensarse como textualidad en lo que Pablo Latapí reconstruye, a partir de sus escritos y discursos, como el Hombre cabal (2005: 25). El máximo ideal humanista de 
Torres Bodet es un hombre completo y equilibrado que desarrolla al máximo sus capacidades; su modelo es Leonardo da Vinci, el "hombre universal". Como ideal de educación este hombre se resume en diez características: integridad, autoestima, noble existencia, virtud, dignidad, elegancia, sencillez, modestia, probidad y honorabilidad (25). Se trata de una síntesis de la cultura y la especialización técnica (25). Podemos decir que algo así como una máquina masculina con razón, sentimientos, ética y estética, que en su campo más amplio de acción, parafraseando a Butler, refuerza un sistema binario, en el cual el género -letrado- refleja el sexo y está limitado por él (2007: 54). Desde este punto de vista, el quehacer biotextual de las minorías letradas internacionales del México que va del siglo XIX al XX no deja de ser el construir -y reforzardicho sistema de binarismos. En estos, acaso, la mujer se dibuja en una paradoja de omisión y contraposición. Así también las diferencias masculinas situadas en espacios fuera de los circuitos letrados.

Por otra parte, y en pugna con otras versiones de masculinidad letrada, sin duda, la de Torres Bodet es una respuesta al hombre recio, curtido, hermético y endurecido por la cuestión mexicana que proponían algunos intelectuales posrevolucionarios. Un hombre que se posiciona tras una máscara de diálogo entre iguales, pues a quien se apela es al mexicano como sujeto homogéneo de lo nacional, y no se incluye a la mujer ni al campesino sin instrucción. De este modo, el diálogo letrado se da sólo entre los varones educados en los salones, grupos y aulas. A este respecto, opina Butler que el "modelo de diálogo" -como modelo de sexo/género liberal"[...] implica que los agentes hablantes poseen las mismas posiciones de poder y hablan con las mismas presuposiciones acerca de lo que es 'acuerdo' y 'unidad' y, de hecho, que ésos son los objetivos que se pretenden" (2007: 68).

En esta línea, ya en 1959 Torres Bodet expresa que

Un mexicano es en quien la enseñanza estimule armónicamente la diversidad de sus facultades: de comprensión, de sensibilidad, de carácter, de imaginación y creación. Un mexicano dispuesto a la prueba moral de la democracia [...] que, fiel a las aspiraciones y a los designios de su país, sepa ofrecer un concurso auténtico a la obra colectiva [...] que incumbe a la humanidad entera, lo mismo en el seno de la familia, de la ciudad y de la nación [...]" (en Latapí, 2005: 35).

La mujer estaría entre estas últimas categorías, podríamos pensar.

Antes, en el discurso inaugural del Congreso de Unificación Magisterial, en 1943, habla del hombre como resultado de "una enseñanza integral", del obrero, el agricultor, el artesano, el artista, el profesionista y el sabio (Torres Bodet, 1985: 17). A esto agrega que "[...] la humanidad necesita hombres, hombres completos; no siervos dóciles. La patria no ansía súbditos, sino hijos y, como todas las madres, ambiciona para sus hijos una dicha fundada en la libertad" (31). Como puede verse, los materiales con los que este internacional educador trabaja son las interconexiones entre urbanización, literatura, capitalismo, educación, ciudadanía y cultura homosocial masculina, sobre todo. Como ejemplo de una opción de vida moderna, Torres Bodet se une al discurso de las "pedagogías masculinas" que se ensayan en la proyección transnacional y en espacios selectos de la educación burguesa. Torres Bodet, situado frente a un panorama internacional de subjetividad, aboga por una idea de "persona", que desde cierta filosofía establece su identidad desde una serie de aspectos internos -o interiorizados - que la determinan 
a través del tiempo. Ante estos ejercicios, Butler pregunta: “¿[E]n qué medida las prácticas reguladoras de la formación y la separación de género determinan la identidad, la coherencia interna del sujeto y, de hecho, la condición de la persona de ser idéntica a sí misma? ¿En qué medida la 'identidad' es un ideal normativo más que un aspecto descriptivo de la experiencia" (2007: 71). La labor del educador-caballero-letrado radica, así, en ese ideal normativo que nunca pierde la función de la lección. La educación en este complejo plano sociocultural es un biopoder-ya que busca situar una "verdad" del sexo, como la llama Foucault (en Butler, 2007: 72; las cursivas son nuestras)_; y esta naturaleza la sitúa un tanto más allá del simple juego de la instrucción y el aleccionamiento. La apelación del educador mexicano al "mexicano", al "hombre", desde esta lectura no deja de ser un llamado a nuevos y funcionales modos de ser persona en un posible y continuado liberalismo letrado. Ahí actúan el texto y el biotexto, o lo que es: el trazo de una vida (letrada) como fuente de textualidad, escritura y modelización del mundo.

Para Salomón Kahan, quien se encarga de "El humanista" en el libro de semblanzas sobre Torres Bodet, este termina por situarse como un verdadero "Ciudadano del mundo"; el poetaeducador-diplomático es un hombre y nada humano le es ajeno, como encarnación viva del Renacimiento. Él es el "hombre cabal", el "hombre integral"; es el hombre como "medida de todas las cosas" (1965: 77). No pensamos que pueda expresarse más claramente. Retornando, una vez más a Butler, para ella es importante insistir que “[...] lo que está funcionando al nivel de la fantasía cultural en último término no puede disociarse de las formas en las que se organiza la vida material" (2007: 302). Es decir, la biotextualidad del hombre ejemplar que emana, como norma, de la figura de Torres Bodet tiene incidencia en la vida y conciencias de los hombres (y mujeres) que se sitúan en el plano de la vida real, por llamarla de una forma coloquial. Dicha biotextualidad generada, celebrada y reproducida por hombres en ámbitos blindados bien puede ser concebida como un saber-poder, siendo este tipo de constructos los que ordenan al mundo. Para Kahan, el "nuevo humanismo" del que Torres Bodet es el hombre más aventajado, surge de una crisis - del humanismo en sí-; pero es que ahí en donde se dice humanismo habría que escribir, acaso, también hombría, caballería, virilidad, masculinidad... La crisis del problema del Hombre es la crisis de problema del hombre; este es el transparente silogismo de la retórica letrada mexicana y de sus personajes de la vida moderna.

A este respecto, pensamos que con la aproximación que se ha acometido sobre la biografía del educador mexicano, concebida como un cuerpo textual, y abordado este como un destacado mediador cultural "entre mundos", nos permite reforzar la definición de lo que concebimos como "pedagogías masculinas"; a decir, dispositivos múltiples de representación y aleccionamiento cuya función es perfilar y re/negociar, en cuanto a los personajes de la vida moderna, definiciones subjetivas mediadas por el poder, así como las identidades sexoculturales en los lindes nacionales. En un sentido más complejo, podríamos hablar incluso de la "consciencia de sî" de los sujetos en cuanto a lo que dichas pedagogías le permiten o no conocer en términos de los órdenes simbólico, imaginario y real que lo atraviesan y prefiguran. Estas "pedagogías masculinas", cabe decir, surgen de una idea amplia de educación; una que supera los límites de lo formal, las instituciones, y se desborda hacia el seno de la vida social y cotidiana. Asimismo, pensamos que sirven, a la hora de ser identificadas desde una mirada múltiple -a la 
vez textual y biotextual一, para definir, entre otras posibles cosas, cómo es que se construye la matriz masculina institucional en el marco de una historiografía dinámica y móvil.

El ideal categórico del hombre, concluimos, cuya máxima expresión estaría cifrada en versiones de ciudadanía letrada, conducida a su vez hacia el progreso por intelectuales en los puestos de instrucción y administración, tiene su expresión mayor en las redes transnacionales de la primera mitad del siglo XX. En este contexto, Torres Bodet es el ejemplo mexicano más destacado, acaso tras Alfonso Reyes, como queda cifrado en las cartas que se escribieron durante toda su vida, ya que cruzaron las fronteras de la lengua, ocuparon los puestos estratégicos y reforzaron redes de intelectualidad múltiple. Desde ahí participaron en la negociación acerca de quién debía ser el Hombre -con mayúscula-, y quiénes los hombres en rangos, cargos y espacios de un nuevo orden de circulación global. En sus íntimas relaciones con poetas, escritores, políticos y diplomáticos entre Europa, América del Sur y México, se situaron a sí mismos y definieron el sistema sexo/género por venir.

En el aire quedan, finalmente, dos cuestiones. La primera piensa en los beneficios si es que toda lectura del pasado es orillada al extremo escondido del sexo/género. La segunda atiende a la idea de que la práctica biotextual se refleja no sólo en su contexto de producción histórica, sino hacia el presente de reconstrucción de sentido historiográfico. El pasado nos habla en clave de género, es lo queremos decir. 
BIBLIOGRAFÍA

Alvarado, María de Lourdes (2004). La educación "superior" femenina en el México del siglo XIX. Demanda social y reto gubernamental. Ciudad de México: CESU/Plaza y Valdés.

Amuchástegui, Ana e Ivone Szasz (2007). "El pensamiento sobre masculinidades y la diversidad de experiencias de ser hombre en México". Amuchástegui, Ana, SZASZ, Ivone (coords.), Sucede que me canso de ser hombre... Relatos y reflexiones sobre hombres y masculinidades en México. Ciudad de México: El Colegio de México.

ASENSI, Manuel (2011). Crítica y sabotaje. Barcelona: Anthropos.

AsEnSI, Manuel. "El teatro de las marionetas en Bajtín. La crítica como sabotaje ante la polifonía”. Signa: Revista de la Asociación Española de Semiótica 23 (2014): 279-296.

ANDERSON, Linda (1997). Women and autobiography in the twentieth century: remembered futures. London/New York: Prentice Hall/Harvester Wheatsheaf.

BARTHES, Roland (1994). "De la obra al texto". El susurro del lenguaje. Más allá de la palabra y la escritura. Barcelona: Paidós.

BARTHES, Roland (1971). Sade, Fourier, Loyola. París: Seuil.

BARTRA, Eli. “Estudios de la mujer. ¿Un paso adelante, dos pasos atrás?”. Politica y Cultura 9 (1997): 201-214.

BlanCO, José Joaquín (1996). "La juventud de los Contemporáneos". Crónica literaria. Un siglo de escritores mexicanos. Ciudad de México: Cal y Arena.

Buffington, Robert (2016). "Men and Modernity in Porfirian Mexico". BeEzley, William H. (ed.). Oxford Research Encyclopedia of Latin American History. Oxford: Oxford University Press.

Buquet, Ana, Coope, Jennifer A., Mingo, Araceli, Moreno, Hortensia (2013). Intrusas en la universidad. Ciudad de México: IISUE-UNAM/PUEG-UNAM.

ButLer, Judith (2006). Deshacer el género. Barcelona: Paidós.

BuTLER, Judith (2007). El género en disputa. El feminismo y la subversión de la identidad. Barcelona: Paidós.

CANO, Gabriela. (2009). "Inocultables realidades del deseo. Amelio Robles, masculinidad (transgénero) en la Revolución mexicana”. CANO, Grabriela, VAughan, Mary Kay, Olсотт, Jocelyn (comps.), Género, poder y política en el México posrevolucionario. Ciudad de México: Fondo de cultura económica/Universidad Autónoma Metropolitana.

ConNELL, Robert William (1995). Masculinities. Sydney: Allen \& Unwin.

DE Certeau, Michel (1993). La escritura de la bistoria. Ciudad de México: Universidad Iberoamericana.

DEL CASTILlo, Alberto (2004). "Imágenes y representaciones de la niñez en México a principios del siglo XX". Historia de la vida cotidiana en México, tomo V, v. 2. Siglo XX. La imagen, zespejo de la vida? Ciudad de México: FCE/COLMEX. 
DEL TORO, José (2015). El cuerpo rosa. Literatura gay, homosexualidad y ciudad. Los espacios de entretenimiento de Ciudad de México a través de la novela. Madrid: Verbum.

DiAz, Jose-Luis (2007). L'écrivain imaginaire: scénographies auctoriales à l'époque romantique. París: Champion.

García de LeÓn, Ma. Antonia (2009). Antropólogas, politólogas y sociólogas. México: Plaza y Valdés.

GONZÁlEZ Romero, Martín H. "Literatura y masculinidad en la primera modernidad mexicana: apuntes de investigación en torno a tres novelas del México independiente”. Revista interdisciplinaria de estudio de género 1 (2015): 157-169.

HeILBRun, Carolyn Gold (1989). Writing a woman's life. New York: Ballantine Books.

IRWIN, Robert McKee (2015). "Colores nunca vistos sobre una tela": nuevos erotismos masculinos de la cultura posrevolucionaria". STANTON, Anthony (ed.). Modernidad, vanguardia y revolución en la poesía mexica (1919-1930). Ciudad de México: COLMEX, s/p.

IRWIN, Robert McKee (1998). "El Periquillo Sarniento y sus cuates: el "éxtasis misterioso" del ambiente homosocial en el siglo diecinueve". Literatura Mexicana. Ciudad de México: UNAM/Centro de estudios literarios: 23-44.

LABRADOR MÉNDEZ, Germán. "MUSA LOCURA. Bioliteratura, política y psicoanálisis en la poesía de la Transición española". La literatura del pobre (2008).

LANDREAu, John y RodrígueZ, Nelson M. (eds.) (2012). Queer Masculinities. A Critical Reader in Education. Londres/Nueva York: Springer.

Latapí, Pablo. "El pensamiento educativo de Torres Bodet: una apreciación crítica". Revista Latinoamericana de Estudios Educativos 3 (2005): 13-44.

LAU, Ana (2006). "Expresiones políticas femeninas en México del S. XX: el Ateneo Mexicano de Mujeres y la Alianza de Mujeres de México". FernándeZ, Maria Teresa, RAmos, Carmen, PORTER, Susie (coords.). Orden social e identidad de género, México, siglos XIX y XX. Guadalajara: CIESAS-UDG.

LAURENTIS, Teresa (1991). "La tecnología del género". Ramos, Carmen (comp.). El género en perspectiva. De la dominación universal a la representación múltiple. Ciudad de México: Universidad Autónoma Metropolitana-Iztapalapa.

LEGGOTT, Sarah (2001). History and autobiography in contemporary Spanish women's testimonial writings. Lewiston: The Edwin Mellen Press.

Luke, Carmen, Gore, Jennifer (eds.) (1992). Feminisms and Critical Pedagogy. Londres/Nueva York: Routledge.

MACÍAS-GONZÁLEZ, Víctor M. (2006). "Hombres de mundo: la masculinidad, el consumo y los manuales de urbanidad y buenas maneras". FernándeZ, María Teresa, Ramos, Carmen, PORTER, Susie (coords.). Orden social e identidad de género. México siglos XIX y XX. Ciudad de México: Universidad de Guadalajara/ Centro de Investigaciones y Estudios Superiores en Antropología Social. 
MACíAS-GONZÁLEZ, Víctor M. "Las amistades apasionadas y la homosociabilidad en la primera mitad del siglo XIX”. Historia y Grafía 31 (2008): 19-48.

MACíAS-GONZÁLEZ, Víctor M. "Apuntes sobre la historiografía de la masculinidad y sus usos para los estudios históricos de género en México”. Navegando 7 (2017): 55-68.

Maingueneau, Dominique. "Escritor e imagen de autor". Pérez, Aina, Torras, Meri. "La autoría a debate: textualizaciones del cuerpo-corpus (una introducción teórica". Tropelías. Revista de Teoría de la Literatura y Literatura Comparada 24 (2015): 1-16.

MartíneZ Carrizales, Leonardo (2017). Tribunos letrados. Aproximaciones al orden de la cultura letrada en el México del siglo XIX. Ciudad de México: Universidad Autónoma Metropolitana.

MiLLER, Nancy K. (1991). Getting personal: feminist occasions and other autobiographical acts. New York: Routledge.

MONSIVÁIS, Carlos (2016). Historia minima de la cultura mexicana en el siglo XX. Ciudad de México: El Colegio de México.

PÉREZ, Aina, TORRAS, Meri. "La autoría a debate: textualizaciones del cuerpo-corpus (una introducción teórica". Tropelías. Revista de Teoría de la Literatura y Literatura Comparada 24 (2015): 1-16.

Peyrou, Florencia. "Familia y política. Masculinidad y feminidad en el discurso democrático isabelino". Historia y política 25 (2011): 149-174.

Poniatowska, Elena (2002). "Las enseñanzas de Torres Bodet". La Jornada. Ciudad de México: La insignia.

Quintanilla, Susana (2008). "Nosotros". La juventud del Ateneo de México. Ciudad de México: Tusquets.

RAMA, Ángel (1998). La Ciudad Letrada. Uruguay: Arca.

REYES, Zoila (2005). Sólo soy una mujer. Oaxaca: MC editores/Universidad Benito Juárez de Oaxaca.

Ríos, Martín F. (2009). Estudios de historia moderna y contemporánea de México 37 (2009): 97-137.

RUBIN, Gayle. "El tráfico de mujeres: notas sobre la 'economía política' del sexo". Nueva Antropología 30 (1986): 95-145.

SANZ, Diana (et al.) (2017). "Cultural Mediators in Cultural History. What do We Learn from Studying Mediators'Complex Transfer Activities in Interwar Belgium?”. BREMS, Elke, RéthelyI, Orsolya, van Kalmthout, Ton (eds.). Doing Double Dutch: The International Circulation of Literature from the Low Countries. Leuven: Leuven University Press.

SIEGEL, Kristi (1999). Women's autobiographies, culture, feminism. New York: Peter Lang.

TORres Bodet, Jaime (1974). Memorias. Equinoccio. Ciudad de México: Porrúa.

Villaurrutia, Xavier (1966). "La poesía de los jóvenes en México". Obras. Poesia/Teatro/Prosas varias/Crítica. Ciudad de México: Fondo de Cultura Económica. 
VV. AA. (1965). Jaime Tores Bodet en quince semblanzas. Ciudad de México: Ediciones Oasis.

VV. AA. (2015). Historia de las mujeres en México. Ciudad de México: Instituto Nacional de Estudios Históricos de las Revoluciones de México/Secretaría de Educación Pública.

WHITE, Hayden (1992). Metahistoria: la imaginación histórica en la Europa del siglo XIX. Ciudad de México: Fondo de Cultura Económica.

ZerTuChe, Fernando (2011). Jaime Torres Bodet. Realidad y destino. Ciudad de México: Fondo de Cultura Económica. 